randomised controlled trial. Lancet. 2018 Jan 20;391(10117):230-240. doi: 10.1016/S0140-6736(17)32137-2.

Disclosure of Interests: None declared.

DOI: 10.1136/annrheumdis-2021-eular.961

\section{POS1107 THE EFFICACY, SAFETY AND OUTCOME AFTER 5-8 YEARS OF PARENTERAL ANTI-OSTEOPOROTIC THERAPY EVALUATED AT A DISTRICT GENERAL HOSPITAL IN THE UK}

Z. Alkutobi ${ }^{1}$, D. Laila2, T. Jones ${ }^{3}$, A. Nandagudi2. ${ }^{1}$ Basildon and Thurrock University Hospitals NHS Foundation Trust, Rheumatology, Basildon, United Kingdom; ${ }^{1}$ Basildon and Thurrock University Hospitals NHS Foundation Trust, Rheumatology, Basildon, United Kingdom; ${ }^{3}$ Basildon and Thurrock University Hospitals NHS Foundation Trust, Internal Medicine, Basildon, United Kingdom

Background: Parenteral anti-osteoporotic medications are frequently recommended for the management of primary and secondary osteoporosis by NICE (1) and EULAR (2) guidelines.

Objectives: This audit aimed at evaluating the efficacy, adherence and safety profile of denosumab $(D)$, zoledronate $(Z)$ and teriparatide $(T)$.

Methods: The data of patients initiating D, Z and T from 2012-2021 were retrospectively reviewed using electronic medical records at Basildon hospital.

Results: We enrolled 146 patients diagnosed with low bone density and on following treatment (3-6 years $D$ (n: 50), 4-5 years $Z$ (n: 50$)$ and 2 years $T$ (n: 46) More than $92 \%$ were Caucasian females; $41.7 \%$ were above 80 years.

$\mathrm{T}$ group had more pronounced reduction in bone mineral density (BMD) with a mean T-score

(spine:-3.9, hip: -2.6, neck of femur: -2.7; followed by Z group (spine: -2.6, hip:-2, neck of femur: -2.5) and $D$ group (spine: -2.3 , hip:-2.2, neck of femur: -2.3).

Primary prevention was in $26 \%$ and secondary prevention in $73.9 \%$; with the commonest fractures at the vertebrae at $40 \%$.

Oral bisphosphonate was the first choice in $63.6 \%$ of the cases (please see graph1). Intolerance, gastric upset or inefficacies were the commonest reasons to avoid them.

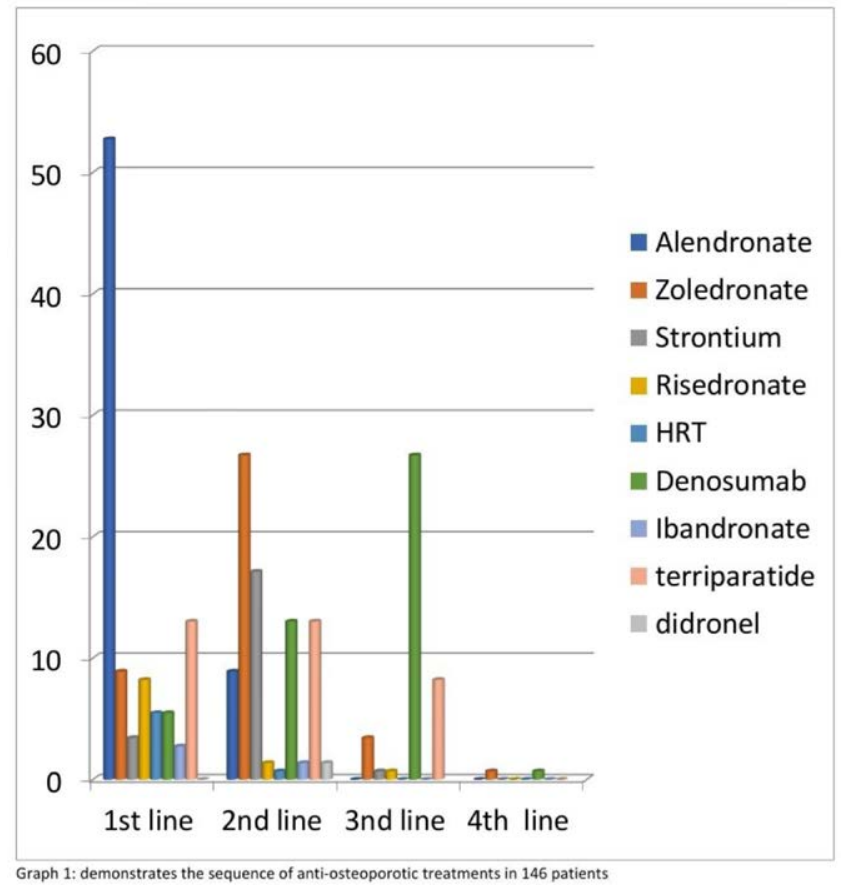

After the 3rd Z or 5th D, DXA scan shows improvements or stability in BMD at both hip and spinal areas in $88 \%$ and $82 \%$ respectively; compared to $69.6 \%$ after completing 2 years of T. The rate of improvement or stability plummeted after the 10th $D$ and 5 th $Z$ (Please see Table 1).
Table 1. Monitoring BMD after courses of D, $\mathrm{Z}$ and T.

\begin{tabular}{|c|c|c|c|c|c|}
\hline $\begin{array}{l}\text { DXA scan: } \\
\text { changes in BMD: }\end{array}$ & $\begin{array}{c}\text { After } \\
\text { the } 5^{\text {th }} D\end{array}$ & $\begin{array}{c}\text { After } \\
\text { the } 10^{\text {th }} D\end{array}$ & $\begin{array}{c}\text { After } \\
\text { the } 3^{\text {rd }} Z\end{array}$ & $\begin{array}{l}\text { After } \\
\text { the } 5^{\text {th }} Z\end{array}$ & $\begin{array}{c}\text { After } \\
2 \text { years of } T\end{array}$ \\
\hline Percentage of scanned patients & $100 \%$ & $90 \%$ & $100 \%$ & $60 \%$ & $71.73 \%$ \\
\hline $\begin{array}{l}\text { Improved or stable BMD at spine or } \\
\text { hip areas }\end{array}$ & $82 \%$ & $75.5 \%$ & $88 \%$ & $85.6 \%$ & $69.6 \%$ \\
\hline $\begin{array}{l}\text { Improved or stable BMD at the spine } \\
\text { but declined at hip area }\end{array}$ & $18 \%$ & $19.9 \%$ & $12 \%$ & $13.3 \%$ & $24.2 \%$ \\
\hline $\begin{array}{l}\text { Declined BMD at both spine and } \\
\text { hip areas }\end{array}$ & & $4.4 \%$ & & & $6 \%$ \\
\hline
\end{tabular}

The course of T was stopped earlier in $28.2 \%$ of the cases due to the difficulty in taking injections or side effects including nausea, gastric upset, myalgia, insomnia, poor renal function, raised PTH, ALP and calcium. Dental issues (not osteonecrosis) were the reason to stop $Z$ and $D$ in $2 \%$ of each group and $8 \%$ choose to discontinue $\mathrm{D}$ after developing other non-related comorbidities. There were no fragility fractures during the treatment courses.

The outcome after reviewing $91.3 \%$ of those who completed or stopped the T course shows $39 \%$ commenced on D whereas $35.7 \%$ and $19 \%$ on $Z$ and alendronate respectively leaving $7.1 \%$ on drug holiday. After completion of the 10 th $D$ $78.5 \%$ of the reviewed patients were continued on further $D$ injections whereas $3.5 \%$ were switched to $\mathrm{T}$ and $17.8 \%$ given drug holiday. For those who were reviewed after the 5 th $Z, 94 \%$ were switched to $D$ and $5.8 \%$ given drug holiday. Conclusion: $\mathrm{D}, \mathrm{Z}$ and $\mathrm{T}$ were well tolerated and could effectively either maintain or improve the BMD at both spinal and hip sites and prevent fragility fractures and $T$ was associated with the most pronounced soar in BMD. There were few cases of deterioration mainly at the hip area with all groups.

Prior bisphosphonate therapy did not show significant influence on the later effects of $D, Z$ or $T$ on BMD. After completion of the treatment for the 3 groups only $30.87 \%$ of the reviewed cases were advised for drug holiday and majority were switched to $D$ as $Z$ and $T$ is limited to 5 and 2 years course respectively. Heterogeneity in decision making exists due to variability in recommending these medications, patient preference and mode of administration. To optimize the adherence and effects of anti-osteoporotic medications, stratified guidelines is required for the long term use of these medications and discontinuation of $D$. REFERENCES:

[1] NICE Pathway: 20 August 2019, http://pathways.nice.org.uk/pathways/ osteoporosis

[2] Kanis JA et al. European guidance for the diagnosis and management of osteoporosis in postmenopausal women. Osteoporos Int. 2019 Jan;30(1):3-44

Disclosure of Interests: None declared.

DOI: 10.1136/annrheumdis-2021-eular.1670

\section{\begin{tabular}{|l|l}
\hline POS1108 & THE ACCURACY OF OSTEOPOROTIC FRACTURE
\end{tabular} RISK PREDICTION IN PATIENTS WITH RHEUMATOID ARTHRITIS USING THE PREDICTIVE MODEL DEVELOPED AT V.A. NASONOVA REASEARCH INSTITUTE OF RHEUMATOLOGY (RUSSIA) AND FRACTURE RISK ASSESSMENT TOOL (FRAX)}

P. Kozhevnikova ${ }^{1}$, P. Kovalenko' ${ }^{1}$, S. Glukhova ${ }^{1}$, I. Dydykina ${ }^{1}$, A. Lila ${ }^{1}{ }^{1}$ V.A. Nasonova Research Institute of Rheumatology, Laboratory for the Study of Comorbid Infections and Safety Control of Drug Therapy, Moscow, Russian Federation

Background: FRAX is a computer-based algorithm that calculates the 10-year probability of a major osteoporotic fracture and the 10-year probability of hip fracture. However, FRAX has several limitations in assessing the risk of fracture in patients with rheumatoid arthritis (RA).

In 2013V.A. Nasonova Reasearch Institute of Rheumatology (Russia) developed a predictive mathematical model for assessing the risk of osteoporotic fractures in RA, which includes 2 main risk factors: cumulative glucocorticoid dose (GC), decrease in BMD in the femoral neck to osteoporosis, and 2 additional factors: for patients under 65 years of age - the presence of ischemic heart disease, and for people over 65 - a history of gastric ulcer or duodenal ulcer.

Objectives: To compare accuracy of osteoporotic fracture risk prediction in patients with RA using the predictive model developed at V.A. Nasonova Rea search Institute of Rheumatology (IR) and FRAX.

Methods: This monocentric (single-center) prospective study included 70 patients with RA, aged 40 to 80 years. The follow-up period - $8.0 \pm 1.2$ years mean age at the baseline was $55.4 \pm 7.8$ years old; the mean disease duration at 
the baseline $-14,7 \pm 10,2$ years. All patients retrospectively calculated the 10 -year probability of fractures and prognostic model developed by the IR.

Results: According to the Fracture Risk Assessment Tool, 32 (46\%) patients had a low risk of osteoporotic fractures, $38(54 \%)$ had a high risk. According to the predictive model of IR $33(47 \%)$ patients had a low risk of osteoporotic fractures, $37(53 \%)$ had a high risk. During the follow-up period, osteoporotic fractures were occurred in $18(26 \%)$ patients: $14(78 \%)$ of them had a high risk of fractures according to the predictive IR model, and $13(72 \%)$ patients - according to the Fracture Risk Assessment Tool. Positive and negative predictive value of the Fracture Risk Assessment Tool was 34\% and $84 \%$, respectively, of the predictive model of IR - $38 \%$ and $88 \%$, respectively. Prognosis of the predictive model of IR in $73 \%$ cases coincided with assessing the 10 -year probability of fracture. Conclusion: The predictive model developed at V.A. Nasonova Reasearch Institute of Rheumatology (Russia) showed a higher sensitivity and specificity in determining the risk of osteoporotic fractures in RA patients vs FRAX algorithm. Disclosure of Interests: None declared.

DOI: 10.1136/annrheumdis-2021-eular.1717

\section{POS1109 MULTIVARIATE ANALYSIS OF RISK FACTORS FOR REDUCED BONE MINERAL DENSITY ASSESSED WITH RADIOFREQUENCY ECHOGRAPHIC MULTI SPECTROMETRY (REMS)}

Z. Batalov ${ }^{1}$, M. Nikolov ${ }^{2}$, N. Nikolov ${ }^{2} .{ }^{1}$ Medical University of Plovdiv, University Hospital Kaspela, Plovdiv, Bulgaria; ${ }^{2}$ UMBAL Dr. Georgi Stranski, Rheumatology, Pleven, Bulgaria

Background: Radiofrequency echographic multi spectrometry (REMS) is an innovative radiation-free approach for the assessment of bone mineral density (BMD) at axial sites. The principle of this technology is based on the analysis of native raw unfiltered ultrasound signals, the so called radiofrequency ultrasound signals, acquired during an echographic scan of the lumbar spine and/or femoral neck. [1]. A previous published study showed a high degree of correlation between the T-score values provided by the two techniques-REMS and dual energy X-ray absorptiometry for both lumbar spine and femoral neck [2]. REMS software outputs information about BMD (g/cm2), T-scores, Z-scores [standard deviations (SD)], percentage of body fat and basal metabolic rate [BMR (kcal/ daily)] [3].

Objectives: The aim of the current study is to investigate the multivariate significant risk factors for reduced BMD through REMS technology.

Methods: In this study, a total of 273 women with mean age 62 years (yrs.) \pm 12 yrs. (range 25-88 yrs.) underwent REMS assessments. Subjects were divided into two groups after acquiring information about the spinal T-scores: 1st group with T-scores $\geq-1$ SD and 2nd group with T-scores <-1 SD. Age, weight, height, body mass index (BMI), basal metabolic rate (BMR), body fat and menopausal status were the risk factors included in the multivariate statistical analyses. Binary logistic regression was used to assess which are the significant risk factors for T-score <-1 SD. Youden's indices were calculated for selecting the cut-off points for each risk factor.

Results: 273 women had mean weight of $70.5 \mathrm{~kg} . \pm 15.7 \mathrm{~kg}$. (range $39.4-127 \mathrm{~kg}$.), mean height $157.1 \mathrm{~cm} . \pm 8.8 \mathrm{~cm}$. (range $100-182 \mathrm{~cm}$.) and mean body mass index (BMI) $28.6 \mathrm{~kg} / \mathrm{cm} 2 \pm 6.1 \mathrm{~kg} / \mathrm{cm} 2$ (range $14.9-47.5 \mathrm{~kg} / \mathrm{cm} 2$ ). The mean body fat of the subjects was $37.8 \% \pm 8.8 \%$ (range $9-52 \%$ ) and the mean BMR was 1274.01 $\mathrm{kcal} /$ daily $\pm 163.17 \mathrm{kcal} /$ daily (range 929.7-1908.4 kcal/daily). 260 women $(95.2 \%)$ were attributed to postmenopausal. Age $(p=0.000)$, BMI $(p=0.015)$, menopause $(p=0.006)$ and BMR $(p=0.000)$ were the multivariate significant risk factors for T-score $<-1$ SD. Odds ratio for the risk factor age was 1.16, so each added year of the women's age increased the risk for T-score $<-1$ SD by $1.16 \%$. Women over the age of $65 \mathrm{yrs}$. showed the highest risk for spinal T-score $<-1 \mathrm{SD}$. The odds ratio of the menopause as a risk factor for spinal T-score $<-1$ SD was 9.54 , so postmenopausal women showed about 9.5 times higher risk of T-score <-1 $\mathrm{SD}$ of the lumbar spine than women who still have their period. The increase of $\mathrm{BMI}$ by one $\mathrm{kg} / \mathrm{cm} 2$ decreased the probability of spinal T-score $<-1$ SD by $0.15 \%$ and the increase of BMR by one $\mathrm{kcal} /$ daily decreased this probability by $0.02 \%$. Women with BMI above $28.63 \mathrm{~kg} / \mathrm{cm} 2$ and those with $\mathrm{BMR}>1331.75 \mathrm{kcal} /$ daily were unlikely to develop spinal T-score $<-1 \mathrm{SD}$.

Conclusion: In the current study, multivariate regression analysis was used to develop a specific REMS-based risk prediction model for spinal BMD, corresponding to T-score <-1 SD. Postmenopausal women over age of 65 yrs. with BMI lower than $28.63 \mathrm{~kg} / \mathrm{cm} 2$ and BMR $<1331.75 \mathrm{kcal} /$ daily were at the highest risk for T-score <-1 SD of the lumbar spine.

REFERENCES:

[1] Pisani P, Renna MD, Conversano F, Casciaro E, Muratore M, et al. (2013) Screening and early diagnosis of osteoporosis through X-ray and ultrasound-based techniques. World J Radiol 5(11): 398-410.

[2] Kirilov N. Analysis of dual-energy x-ray absorptiometry images using computer vision methods. (2020) Trakia Journal of Sciences, Vol. 18, Suppl. 1, pp 114-117.
[3] Kirilova E, Kirilov N, Popov I, Vladeva S. (2019) Bone mineral density of lumbar spine and femoral neck assessed by novel echographic approach-Radiofrequency Echographic Multi Spectrometry (REMS). Clin. Cases Miner. Bone Metab., 16 (1), pp. 14-17.

Disclosure of Interests: None declared.

DOI: 10.1136/annrheumdis-2021-eular.1768

\section{POS1110 RELIABILITY OF VERTEBRAL FRACTURE ASSESSMENT ON DUAL-ENERGY X-RAY ABSORPTIOMETRY}

M. Yasmine ${ }^{1}$, S. Mariem ${ }^{1}$, S. Miladi ${ }^{1}$, A. Fazaa ${ }^{1}$, E. Fguiri ${ }^{1}$, L. Souebni ${ }^{1}$, K. Ouenniche ${ }^{1}$, S. Kassab ${ }^{1}$, S. Chekili ${ }^{1}$, K. Ben Abdelghani ${ }^{1}$, A. Laatar ${ }^{1}$. ${ }^{1}$ Mongi Slim Hospital, Rheumatology, Tunis, Tunisia

Background: Vertebral Fracture Assessment (VFA) is a new feature available on modern densitometers. Yet, the assessment of vertebral fracture (VF) status has not become standard practice.

Objectives: Our study aimed to evaluate the reliability of VFA as assessed by a rheumatologist and a radiology technician.

Methods: We conducted a cross-sectional study assessing the performance of low-radiation single energy x-ray absorptiometry VFA for the detection of VF. We selected patients who were assessed for osteoporosis according to screening protocols. Bone mineral densitometry was measured using standard methods over the lumbar spine L1-L4, the total proximal femur, and results were expressed as T-scores. All VFA were independently evaluated by 2 experienced readers: a rheumatologist and a radiology technician for the identification of VF (T4-L4). VF was classified according to the Genant grading system: grade 1 for an anterior, mid or posterior reduction of 20-25\% in vertebral height; grade 2 for a reduction of 25-40\% and grade 3 for a reduction of more than $40 \%$ in vertebral height. A score for the inter-rater reliability between the readers was expressed using the kappa statistic. Results: One hundred patients were included with a mean age of $66.9 \pm 9.5$ years [46.7-83] years. There was a female predominance $(91 \%)$. Nearly half of patients had osteopenia (48.9\%), $27.7 \%$ had osteoporosis and $23.4 \%$ had a normal bone mineral density. On VFA scans, the non-visible vertebra was mostly located in the upper thoracic spine (60\%). The mean number of VF was $1.2[0-3]$ for both readers. According to the doctor's evaluation, $25 \%$ of patients had at least one VF, of which $75.9 \%$ had a Genant grade 1, $17.2 \%$ had a Genant 2, and $6.9 \%$ had a VF grade 3. According to the technician evaluation, at least one VF was found in $36 \%$ of patients. A grade 1 was assessed in $91.7 \%$ of cases, a grade 2 in $8.3 \%$ of patients but no VF grade 3 was assessed. A kappa score for the inter-rater reliability between the readers for VFA was $0.545(p=0.000)$. The overall agreement by grade between the readers was $0.785(p=0,000)$. The exclusion of non-visible vertebra resulted in a better agreement $(k=0.853)$. Further analysis excluding vertebra T4 to D10, revealed a very good agreement $(\mathrm{k}=0.9)$.

Conclusion: Our study showed a low agreement between the readers on VFA and a better agreement when non-visible vertebrae were excluded. Thus, caution should be advocated when relying exclusively on this device.

Disclosure of Interests: None declared.

DOI: 10.1136/annrheumdis-2021-eular.1866

\section{POS1111 DIAGNOSIS OF OSTEOPOROSIS USING RADIOFREQUENCY ECHOGRAPHIC MULT SPECTROMETRY (REMS) AT THE LUMBAR SPINE IN PATIENTS WITH DIFFERENT BODY MASS INDEX}

B. Cortet ${ }^{1}$, E. Dennison ${ }^{2}$, A. Diez-Perez ${ }^{3}$, M. Locquet ${ }^{4}$, M. Muratore ${ }^{5}$, D. Ovejero Crespo $^{3}$, X. Nogués ${ }^{3}$, M. L. Brandi ${ }^{6,7} .{ }^{1}$ University-Hospital of Lille, Department of Rheumatology and EA 4490, Lille, France; ${ }^{2}$ Southampton General Hospital, University of Southampton, MRC Lifecourse Epidemiology Unit, Southapmton, United Kingdom; ${ }^{3}$ IMIM (Hospital del Mar Medical Research Institute), Centro de Investigación Biomédica en Red en Fragilidad y Envejecimiento Saludable (CIBERFES), ISCIII, Musculoskeletal Research Group, Barcelona, Spain; ${ }^{4}$ University of Liège, Department of Public Health, Epidemiology and Health Economics, Liège, Belgium; ${ }^{5}$ Vito Fazzi Hospital, ASL-LE, O.U. of Rheumatology, Lecce, Italy; ${ }^{6}$ FIRMO Foundation, Florence, Italy; ${ }^{7}$ The National Observatory on Fragility Fractures, Florence, Italy

Background: In recent years, the technology based on the analysis of raw ultrasound signals, Radiofrequency Echographic Multi Spectrometry (REMS), has been validated against Dual-energy X-ray Absorptiometry (DXA) for the diagnosis of osteoporosis and risk fracture prediction.

Objectives: The aim of this multicenter observational study was to evaluate the diagnostic performance of REMS with respect to DXA in patients with different body mass index (BMI) categories.

Methods: The inclusion criteria were: Caucasian women; age between 30 and 90 years; referral by their clinician for spinal DXA assessment; absence of significant walking impairment; signed informed consent. 